\title{
Lipomyelomeningocele-Controversies in Management
}

\author{
Abhishek Singh ${ }^{1}$ Samarendranath Ghosh ${ }^{1}$ Anup Kr. Chaudhuri ${ }^{1}$ Shahid Iftekhar Sadique ${ }^{1}$ \\ Subhamitra Chaudhuri'
}

${ }^{1}$ Department of Neurosurgery, Bangur Institute of Neurosciences,

I.P.G.M.E.\& R., Kolkata, West Bengal, India

\begin{abstract}
Address for correspondence Abhishek Singh, MBBS, MS, MCH (Neurosurgery) (Resident), Department of Neurosurgery, Bangur Institute of Neurosciences, I.P.G.M.E.\&R., Kolkata 700025, West Bengal, India (e-mail: divyajsingh4@gmail.com).
\end{abstract}

Indian J Neurosurg 2018;7:5-7

\begin{abstract}
Keywords

- lipomyelomeningocele

- controversies

- management

Management of lipomyelomeningocele is one of the most discussed and controversial topics in recent years. Till date, there is no consensus on the most appropriate mode of management for lipomyelomeningocele, particularly in asymptomatic patients. This article tries to sort out controversies associated with lipomyelomeningocele based on various literatures and also takes into account patient profile of a developing country.
\end{abstract}

\section{Introduction}

Even though our knowledge on various types of spinal dysraphism has gone a long way, courtesy improvement in our understanding on etiopathogenesis and, moreover, embryologic aspect associated with spinal dysraphism. Still, controversies persist regarding its most appropriate mode of management. Controversy is even higher in certain closed form of spinal dysraphism such as lipomyelomeningocele, especially when the patient is asymptomatic. This article tries to sort out controversies associated with lipomyelomeningocele based on various literatures and also takes into account patient profile of a developing country.

Johnson first described a lipomyelomeningocele in 1857, ${ }^{1}$ but Rogers and colleagues are credited with introducing the term "lipomyelomeningocele" in $1971 .{ }^{2}$ Incidence of lipomyelomeningocele is 1 in 4,000 live births with slight female preponderance. Not only the management but also when we go through available literatures we find that definition of lipomyelomeningocele itself is controversial. Lipomyelomeningocele may be defined as a defect in the spine through which the lipomatous substance arising from subcutaneous tissue is inserted into spinal canal. Now, the controversial point here is that whether there is any neural tissue outside the spinal canal in case of lipomyelomeningocele. If we go through the embryology, we find that lipomyelomeningocele is due to defect during secondary neurulation at the stage of dysjunction. ${ }^{3,4}$ Dysjunction is the process by which neural ectoderm gets separated from the cutaneous ectoderm, and if somehow premature dysjunction occurs, a dorsal cleft is left, as a result of which para-axial mesenchyma gets access to the developing neural tube, prevents its closure, and induces the totipotent mesenchymal cells to differentiate into adipocytes. Spina Bifida and Hydrocephalus Association of Canada very simply defines lipomyelomeningocele as an abnormal fat accumulation that starts below the skin and extends through an opening in the spine to the spinal cord. This clearly states that the defect starts from outside and extends into the spinal canal and not vice versa, so there should not be any neural component outside the canal. However, in some cases we may find neural tissue outside the spinal canal, and that is probably due to the expansion of subarachnoid space.

\section{Classification}

There are various classification systems of lipomyelomeningocele based on lipoma-cord interface, of which Chapman classification system is well known. According to Chapman, lipomyelomeningocele is classified mainly into three types ${ }^{5}$ :

1. Dorsal: In dorsal type of lipomyelomeningocele, lipoma is attached to the dorsal aspect of conus medullaris, and there is no neural tissue within the substance. Therefore, from surgical point of view, this type is easier to dissect and complete removal of lipomatous tissue can be attempted.

2. Caudal or terminal: In this type, lipoma is attached to the terminal part of conus medullaris, and unlike dorsal type, we may find neural tissue within the lipomatous substance. Therefore, it is difficult to remove surgically, received

February 20, 2018

accepted after revision

March 27, 2018

published online

May 14, 2018
DOI https://doi.org/

10.1055/s-0038-1649525.

ISSN 2277-954X.
Copyright (02018 Neurological

Surgeons' Society of India
License terms

() (1) $\ominus \circledast$ 


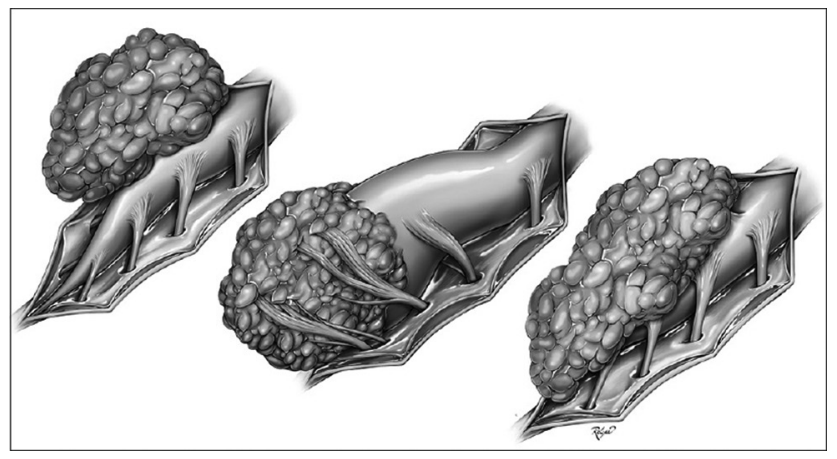

Fig. 1 Different types of lipomyelomeningocele.

and a temptation to completely remove lipoma may result in damage to the neural tissues. ${ }^{6}$

3. Transitional: This may be considered to be a subtype of dorsal variety where the lipoma starts from the conus medullaris and extends up to the filum terminale ( - Fig. 1).

As far as diagnosis is concerned, ultrasonography and magnetic resonance imaging (MRI) are supposed to substantially aid in diagnosis as well as planning of treatment, both pre- and postnatally.

\section{Management}

Management of lipomyelomeningocele is one of the most discussed and controversial topics in recent years. Till date, there is no consensus on the most appropriate mode of management for lipomyelomeningocele, particularly in asymptomatic patients. In various studies from different groups, it is suggested that there are progressive neurologic, urologic, and orthopaedic deficits in patients with lipomyelomeningocele if they are left untreated. Keating et al reported that more than $92 \%$ of older children presented with urinary incontinence in comparison to $26 \%$ in infants. ${ }^{7,8} \mathrm{Kanev}$ and Bierbrauer demonstrated that most of the children younger than 6 months who were asymptomatic gradually presented with neurologic and urologic dysfunction on follow-up for longer time. ${ }^{9}$ Similar findings were reported by Hoffman and colleagues who demonstrated an $85 \%$ deterioration in children who were left untreated. ${ }^{10}$ However, study from Paris and Osaka group reported progressive neurourologic deficits in patients who were operated upon prophylactically too. Therefore, in an endeavor to minimize the controversy, we have tried to individualize the treatment and divided the patients into three specific groups:

\section{Patients expected to have poor surgical outcome ${ }^{11}$ :}

- Patients with major associated congenital defects of other system

- Megalencephaly at birth

- Patients with poor general condition

- Patients with total paralysis of limbs

Patients of this group are poor surgical candidates not only due to associated comorbidities and poor general condition but also due to poor neurourologic outcome following surgery. Therefore, surgery should be avoided in these patients, and conservative management should be considered a reasonable option.

\section{Symptomatic patients}

Even though there is lot of controversy regarding the most appropriate mode of treatment for lipomyelomeningocele, it is certain that the earlier the intervention, the better is the prognosis in symptomatic patients. Even if an asymptomatic patient is on conservative management, there should be no doubt that surgical intervention should be contemplated as soon as the symptom arises. Most common symptom in lipomyelomeningocele is urologic dysfunction that appears prior to motor and sensory loss, and the patient should be asked to report as soon as such symptom arises.

\section{Asymptomatic patients}

Management of this group of patients is most controversial. There are two schools of thought regarding management in asymptomatic patients. One favoring the conservative approach suggests that if we operate on an asymptomatic patient, there are chances that the asymptomatic patient will be rendered symptomatic, and second, chances of urinary tract infection (UTI), hydronephrosis, and other urologic complications increase in patients operated for lipomyelomeningocele than other cases of closed spinal dysraphism. ${ }^{12}$ However, the group favoring surgical approach advocates that there is progressive neurologic, urologic, and orthopaedic deficiency in almost all patients who are left untreated, ${ }^{13}$ and second, with advancement in pediatric anesthesia, electrophysiologic monitoring, and perioperative care, these patients can be operated upon safely.

Now, we are of the view that even though there is lot of controversy regarding the most appropriate mode of management of lipomyelomeningocele in literatures, they uniformally agree in two points. First, if the patient is left untreated, progressive neurourologic deficit is a rule rather than an exception, and second, preoperative neurourologic status is a prognostic factor in determining the postoperative outcome. Most of the available literatures while documenting the efficacy of conservative management in asymptomatic patients have probably failed to analyze association of lipomyelomeningocele with tethered cord. Patients with lipomyelomeningocele may be asymptomatic in early childhood, but its association with tethered cord will eventually lead to symptoms that may be difficult to treat on a later stage when the symptoms have already progressed.

\section{Conclusion}

Lipomyelomeningocele, if left untreated, will eventually lead to progressive neurourologic deficits and early surgical intervention carries a favorable prognosis. Therefore, surgical intervention can be considered the treatment of choice even in asymptomatic cases of lipomyelomeningocele, especially considering the patient profile of a developing country where most patients are either lost to follow-up or report at a late stage of disease when treatment becomes difficult. 


\section{References}

1 Johnson A. Fatty tumor from the sacrum of a child, connected with the spinal membranes. Trans Pathol Soc (London) 1857;8:16-18

2 Rogers HM, Long DM, Chou SN, French LA. Lipomas of the spinal cord and cauda equina. J Neurosurg 1971;34(3):349-354

3 McLone DG, Naidich TP. Terminal myelocystocele. Neurosurgery 1985;16(1):36-43

4 Naidich TP, McLone DG. Spinal dysraphism. In: Newton TH, Potts DG, eds. Modern Neuroradiology. Computed Tomography of the Spine and Spinal Cord. Vol. 1. San Francisco, CL: Clavadel Press; 1983:299-315

5 Chapman PH. Congenital intraspinal lipomas: anatomic considerations and surgical treatment. Childs Brain 1982;9 (1):37-47

6 McLone DG, Mutluer S, Naidich TP. Lipomeningoceles of the conus medullaris. In: Raimondi AJ, ed. Concepts in Pediatric Neurosurgery .Vol. 3. Basel, Switzerland: S. Karger; 1983:170-177
7 Sutton LN. Lipomyelomeningocele. Neurosurg Clin N Am 1995;6(2):325-338

8 Keating MA, Rink RC, Bauer SB, et al. Neurourological implications of the changing approach in management of occult spinal lesions. J Urol 1988;140(5 Pt 2):1299-1301

9 Kanev PM, Bierbrauer KS. Reflections on the natural history of lipomyelomeningocele. Pediatr Neurosurg 1995;22 (3):137-140

10 Hoffman HJ, Taecholarn C, Hendrick EB, Humphreys RP. Management of lipomyelomeningoceles. Experience at the hospital for sick children, Toronto. J Neurosurg 1985;62(1):1-8

11 Ramamurthi B. Problems in spina bifida in developing countries. J Indian Med Assoc 1990;88(6):151-152

12 Macejko AM, Cheng EY, Yerkes EB, Meyer T, Bowman RM, Kaplan WE. Clinical urological outcomes following primary tethered cord release in children younger than 3 years. J Urol 2007;178(4 Pt 2):1738-1742, discussion 1742-1743

13 Cochrane DD, Finley C, Kestle J, Steinbok P. The patterns of late deterioration in patients with transitional lipomyelomeningocele. Eur J Pediatr Surg 2000;10(Suppl 1):13-17 